\title{
Laparoscopic Adrenalectomy: Retroperitoneal Approach
}

\author{
Ashley K. Cayo • Tracy S. Wang
}

Published online: 22 December 2012

(C) Springer Science + Business Media New York 2012

\begin{abstract}
Laparoscopic adrenalectomy has become the gold standard for removal of benign adrenal masses. Despite initial concerns about safety, a long learning curve, and unfamiliarity of anatomy from the posterior approach, the posterior retroperitoneoscopic approach is now the preferred technique at many institutions, and offers several advantages over the transperitoneal approach, including direct access to the adrenal gland, avoiding negotiating scar tissue from previous abdominal operations, and allowing for bilateral surgery without patient repositioning. This review outlines the operative technique, indications and precautions for the posterior retroperitoneoscopic adrenalectomy.
\end{abstract}

Keywords Laparoscopic adrenalectomy ·

Retroperitoneal adrenalectomy · Transabdominal adrenalectomy · Posterior retroperitoneoscopic .

Pheochromocytoma $\cdot$ Cushing's syndrome $\cdot$ Corticalsparing adrenalectomy

\section{Introduction}

Following the introduction of laparoscopic adrenalectomy in 1992 [1], the procedure, traditionally done by a transabdominal approach, has become the standard for benign adrenal masses. In 1995, Mercan et al. [2] described a new,

A. K. Cayo - T. S. Wang $(\bowtie)$

Division of Surgical Oncology, Department of Surgery, Medical College of Wisconsin, 9200 W. Wisconsin Avenue, Milwaukee, WI 55326, USA

e-mail: tswang@mcw.edu

A. K. Cayo

e-mail: acayo@mcw.edu minimally invasive approach with the first description of the laparoscopic retroperitoneal adrenalectomy in a series of 11 patients. While not initially widely embraced, due to concerns about inadequate working space, less familiar anatomical landmarks, and a greater learning curve, the laparoscopic posterior retroperitoneal adrenalectomy ('retroperitoneoscopic adrenalectomy') has recently become the preferred technique at many institutions [3-8, $9 \bullet \bullet, 10,11 \bullet \cdot$ ]. Walz et al. [3-7] described a modification of the technique using higher insufflation pressures, and have since demonstrated success with the procedure. In 2006, Walz et al. reported a series of 560 procedures done via the posterior retroperitoneal approach, to date the largest series reported, showing a $0 \%$ mortality, $1.3 \%$ major and $14.4 \%$ minor complication rate, with a conversion to open rate of only $1.9 \%$. They therefore concluded that the technique can be done safely and quickly for a variety of adrenal pathologies, including non-functioning tumors, ACTH-independent or -dependent hypercortisolism (including ACTH-dependent bilateral hyperplasia), pheochromocytoma, primary hyperaldosteronism, virilizing adenoma, and adrenal metastases [7]. In the United States, several institutions have described their experience with the technique popularized by Walz and also have reported similarly successful clinical outcomes with minimal morbidity and mortality $[8,9 \bullet \cdot, 10,11 \bullet \cdot]$. Here we review the operative technique and current literature regarding the posterior retroperitoneal approach to laparoscopic adrenalectomy.

\section{Operative Technique}

This operative technique has been described by Walz et al. [7], Perrier et al. [8] and Lee [12]. After induction of 
general anesthesia in the supine position, the patient is transferred to the prone jackknife position, with support that allows the abdominal wall to hang unconstrained; doing so helps to expand the retroperitoneal space. The hips and knees are positioned at ninety degree angles,

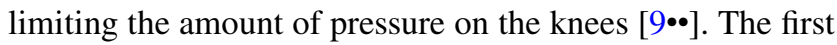
$1.5 \mathrm{~cm}$ incision is made just below the tip of the 12th rib. The subcutaneous tissues are then divided sharply with scissors and the fascia of the retroperitoneal space is entered. Blunt dissection is performed medially and laterally to create space for the insertion of the two additional ports. With the index finger inside the retroperitoneal space, a 5-mm medial trocar is inserted just lateral to the paraspinous muscle about $3 \mathrm{~cm}$ below the 12th rib. This port is directed cranially at a $45^{\circ}$ angle. Again using the index finger to guide placement in the retroperitoneal space, a $5-\mathrm{mm}$ trocar is placed $4-5 \mathrm{~cm}$ lateral to the initial incision below the 11th rib. Finally, a blunt $10-12 \mathrm{~mm}$ trocar with an inflatable balloon is inserted into the initial incision (Fig. 1) [12]. Pneumoretroperitoneum is then established with $\mathrm{CO}_{2}$ to maintain a pressure of 20-28 mmHg.

A $10-\mathrm{mm} 30^{\circ}$ endoscope is then inserted into the middle trocar until the retroperitoneal space is created using a combination of blunt and sharp dissection. The scope is then changed to a $5-\mathrm{mm} 30^{\circ}$ scope and inserted in the medial trocar. The retroperitoneal space below the diaphragm is then created by pushing down on the fatty tissue and entering Gerota's fascia to identify the superior pole of the kidney, which serves as the major landmark during dissection. The tissue superior to the kidney containing the adrenal gland is dissected first; the tissues are elevated and separated from the kidney by placing downward pressure on the kidney and use of a electrocautery device such as the

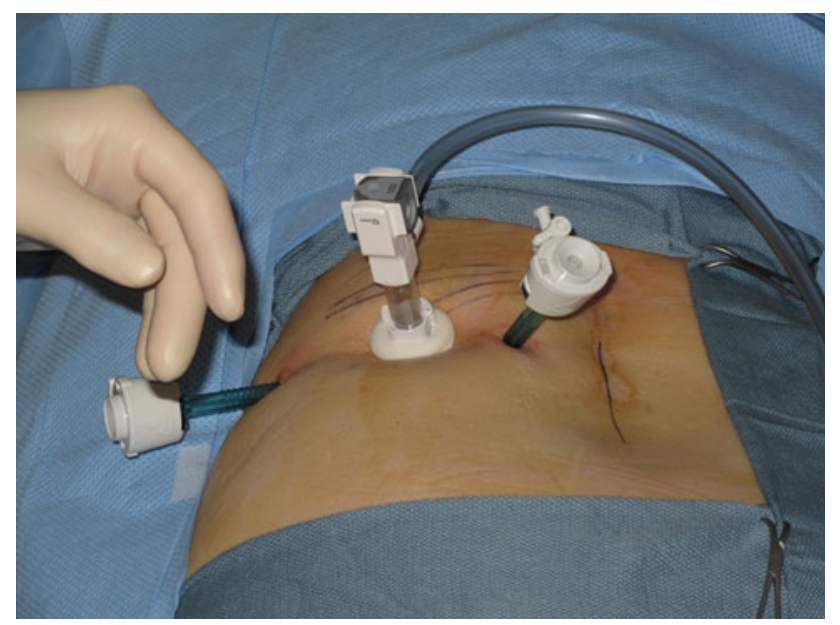

Fig. 1 Port placement for a left-sided posterior retroperitoneoscopic adrenalectomy
Harmonic scalpel or Enseal device. The adrenal vein is then identified, clipped and divided. The phrenic vein may be divided if needed, but can often be preserved. The adrenal gland is then dissected from the remaining retroperitoneal attachments and an endocatch bag is placed through the middle trocar for extraction of the gland. After achieving adequate hemostasis, the fascia of the 10-mm trocar site is closed with a figure-of-eight suture. The skin of all port sites are closed with a subcuticular stitch. The patient is then returned to the supine position and extubated. A chest X-ray is obtained in the recovery area to ensure that a pneumothorax has not occurred.

\section{Precautions}

One of the initial concerns with the posterior retroperitoneoscopic adrenalectomy was the inability to have adequate working space in the retroperitoneum with traditional insufflation pressures. Despite initial concern that higher insufflation pressures would decrease venous return and cause hypotension due to compression of the inferior vena cava, it has subsequently been shown that patients do not have a decrease in cardiac output and have normal filling pressures with higher insufflation pressures [3, 13]. In fact, when intra- and extrathoracic inferior vena cava pressures were measured in patients undergoing both laparoscopic cholecystectomy and laparoscopic posterior retroperitoneal adrenalectomy, it was demonstrated that cardiac filling decreased when intraperitoneal insufflation pressures were greater than $15 \mathrm{mmHg}$, but there was no change in cardiac filling with retroperitoneal insufflation pressures greater than $15 \mathrm{mmHg}$ [14]. The use of higher insufflation pressures (up to $28 \mathrm{mmHg}$ ), have allowed for adequate working space while also creating a bloodless operative field [3, $8,13,14]$.

Laparoscopic posterior retroperitoneal adrenalectomy may also be difficult in patients who are morbidly obese. Walz et al. described the need to convert to the transabdominal approach in two patients $(22 \%)$ because of patient size (BMI >45), which caused compression of the retroperitoneum by abdominal organs when placing the patient in the prone position. Despite high insufflation pressures, they were unable to create an adequate working space [7]. Similarly, Dickson et al. [9••] reported that BMI affected operative time; patients with a BMI $<30$ had a significantly shorter operation than those with a BMI $\geq 30$ (105.7 vs. 125.0, $p=0.01)$. In this same study, they did, however, report success in the retroperitoneal approach in eight patients with $\mathrm{BMI} \geq 40$, concluding that obesity makes the case more technically challenging, and therefore should be chosen carefully and performed by surgeons experienced in this surgical approach. 
Other potential complications of the procedure include pneumothorax, subcutaneous emphysema of the neck and chest, bleeding, and wound infections. Pneumothorax can occur if the pleural space is violated either during placement of trocars or dissection; however, the rate of pneumothorax is reported to range between $<1-3.4 \%[7,8$, 9••]. Palpable subcutaneous emphysema can also occur; however, patients tend to be asymptomatic and their hospital course is not altered [8].

\section{Laparoscopic Adrenalectomy: The Posterior Retroperitoneal Versus Transabdominal Approach}

Numerous authors have investigated the differences between the posterior retroperitoneal and transabdominal laparoscopic approaches [15, 16, 17••, 18-20]. Rubinstein et al. [15] reported a prospected randomized trial comparing the two approaches; 57 patients with benign adrenal pathology were randomized to the transabdominal approach (25 patients) or the retroperitoneal approach (32 patients). Patients with previous surgery in the same quadrant of interest were excluded. The authors found no difference in operative time, blood loss, length-of-stay, or complication rates. In each group, one patient required conversion to an open procedure. The only statistically significant difference found was in average convalescence time, defined as the period needed for complete recovery from the physical aftereffects of surgery, which was 4.7 weeks in the transabdominal group and 2.3 weeks in the retroperitoneal group $(p=0.02)$. They therefore concluded that laparoscopic adrenalectomy can be done safely by either approach for benign lesions, and therefore selection of approach should be determined by experience and preference of the surgeon or patient characteristics [15].

Berber et al. [16] reported their retrospective comparison of the two approaches in 172 cases for both benign and malignant lesions. They found that the posterior retroperitoneal approach was used more frequently in patients with previous abdominal surgery and those with aldosterone-secreting tumors and Cushing's syndrome, and less frequently in patients with pheochromocytomas and tumors $>6 \mathrm{~cm}$. With regards to outcomes, they found no difference in operative times; however, blood loss was greater in the transabdominal group $(35 \pm 7$ vs. $25 \pm 6 \mathrm{~mL}$, $p=0.05$ ) and a higher percentage of patients in the transabdominal group were hospitalized for more than 1 day (43 vs. $18 \%, p=0.05$ ) [16]. Lee et al. retrospectively analyzed 43 laparoscopic adrenalectomies and found shorter operative times $(87.2 \pm 27.6$ vs. $108.3 \pm 34.5 \mathrm{~min}$, $p=0.042)$ and shorter return to oral intake $(0.88 \pm 0.33$ vs. $\quad 1.16 \pm 0.47$ days, $p=0.043)$ in the posterior retroperitoneal group. Interestingly, they also reported less use of analgesia in the posterior retroperitoneal group $(1.29 \pm 1.21$ vs. $3.84 \pm 3.28$ times analgesics were used, $p=0.004)[17 \bullet \bullet]$.

Ramacciato et al. [18] reported the results of their retrospective analysis of 171 laparoscopic adrenalectomies. In contrast to Berber and Lee, they found that operative time $(110.8 \pm 40.8$ vs. $151.5 \pm 45.2 \mathrm{~min}, p<0.001)$ and blood loss $(183.3 \pm 216.7$ vs. $421.2 \pm 205.3, p=0.001)$ was significantly lower in the transabdominal group than in the posterior retroperitoneal group. However, patients had a faster return to oral intake in the posterior retroperitoneal group (1.2 \pm 0.5 vs. $1.6 \pm 0.8, p=0.006)$, as also was shown by Lee et al. Overall, the authors conclude that the two approaches are safe and can have benefits for different populations [16, 17••, 18].

In a recent meta-analysis of 21 studies comparing the transabdominal and posterior retroperitoneal approaches, there was no statistically significant difference between the two approaches with respect to operative time, blood loss, hospital length-of-stay, time to oral intake, morbidity (surgical site infection, pneumothorax, post-operative bleeding) and mortality [21]. As with previous institutional studies, the findings of this study suggest that both the laparoscopic transabdominal and posterior retroperitoneal approaches can be performed with acceptable rates of morbidity.

\section{Indications}

Laparoscopic adrenalectomy can be performed for a variety of adrenal pathology. In 2008, Perrier et al. [8] reported a series of 68 patients undergoing posterior retroperitoneoscopic adrenalectomy for functional tumors (pheochromocytoma, Cushing's disease/syndrome, aldosteronoma, and virilizing tumor), non-functional adenomas, and isolated adrenal metastases. In this study, they reported a median operative time of $121 \mathrm{~min}$, a complication rate of $15.9 \%$ and a mortality rate of $0 \%$. They updated their series in 2011, with 118 patients and compared their initial experience (68 patients) with the technique to their subsequent experience (50 patients). They found no statistical difference between the groups regarding operative time (110 vs. $118 \mathrm{~min}, p=0.29)$, complication rate (15.9 vs. $7.7 \%$, $p=0.29)$ or conversion rate $(9.5$ vs. $1.9 \%, p=0.19)$, and therefore concluded that proficiency with laparoscopic posterior retroperitoneal adrenalectomy can be achieved in a short time period [9••].

The selection of patients appropriate for posterior retroperitonoscopic adrenalectomy is critical for the surgeon. The technique may be preferred in patients with previous abdominal surgery, as it avoids surgical adhesions and 
increased risk of injury to other organs by removing the necessity of mobilizing the liver and hepatic flexure of the colon on the right and the spleen, splenic flexure of the colon, and tail of the pancreas on the left. As described by Perrier et al. [8], the technique avoids entry into the abdominal and pleural spaces; therefore in patients with multiple abdominal operations it is not necessary to navigate intra-abdominal scar tissue. However, the retroperitoneal approach may be more difficult in obese individuals. As stated earlier, operative times have been shown to be increased in patients with $\mathrm{BMI} \geq 30$. Although a high BMI does not preclude the posterior retroperitoneoscopic approach, the selection of these patients needs to be carefully considered $[9 \cdot \bullet]$.

Tumor size has also been cited as an important factor to consider in this approach. Most authors report a size criteria of $<6 \mathrm{~cm}$ in greatest diameter as the threshold for laparoscopic retroperitoneal adrenalectomy $[8,9 \cdot \bullet, 10$, 22••]. However, Walz et al. [7, 23] and colleagues have reported success in tumors up to $10 \mathrm{~cm}$, although they stress the importance of experience with the procedure in these patients.

Recently, Agcaoglu et al. [22••] reported an algorithm based on anthropometric parameters using computed tomography to select patients for transabdominal or retroperitoneoscopic adrenalectomy. In this series of 82 patients, the posterior retroperitoneoscopic approach was used for patients with a distance from Gerota's fascia to skin less than $5 \mathrm{~cm}$ and the 12th rib was at or rostral to the level of the renal hilum.

\section{Pheochromocytoma}

While there was initially concern for any minimally invasive approach to resecting pheochromocytomas given the potential adverse hemodynamic reaction to pneumoperitoneum/pneumoretroperitoneum and gland manipulation, as well as the potentially increased technical difficulty of removing these often larger and more vascular tumors laparoscopically, several groups have evaluated the safety of the laparoscopic transabdominal and posterior retroperitoneal approaches for patients with pheochromocytoma [24-31]. Dickson et al. [25] favored the posterior retroperitoneoscopic approach, citing decreased operative times (99 vs. $145 \mathrm{~min}, p<0.001)$, blood loss ( 8.4 vs. $123.8 \mathrm{~mL}$, $p=0.02)$ and length-of-stay (1.9 vs. 3.1 days, $p<0.01)$ when compared to the transabdominal approach. $\mathrm{Li}$ and $\mathrm{Li}$ [26] reported similar outcomes to Dickson et al., while also showing that there was no significant difference between the transabdominal and posterior retroperitoneal group in fluctuation in blood pressure during or after the operation; therefore, also favoring the retroperitoneal approach. In contrast, Gockel et al. [27] reported less-frequent intra-operative blood pressure peaks with shorter operative times in patients undergoing transabdominal adrenalectomy. Overall, however, it appears that the posterior retroperitoneoscopic adrenalectomy can be performed by surgeons experienced in this operative approach in patients with pheochromocytoma.

\section{Cushing's Syndrome}

Due to the high incidence of comorbidities in patients with an overproduction of cortisol, surgery in these patients historically has been a challenge, with reported morbidity rates of $7-13 \%$ and mortality rate of $2.3 \%[32,33]$. The safety of laparoscopic adrenalectomy, in particular done by the retroperitoneal approach, has been described $[6,34$, 35]. In 2010, Alesina et al. [34] reported their experience with posterior retroperitoneoscopic adrenalectomy for 170 patients with Cushing's syndrome. The cohort was divided into those with clinical and subclinical Cushing's syndrome. In this series, both mortality and incidence of major complications was zero. Minor complications were reported in $5.3 \%$. The mean operating time $(58 \pm 36 \mathrm{~min})$, is similar to operating times for other pathologies, and did not differ between the clinical and subclinical groups [7, 34]. Therefore, despite the challenges due to obesity and comorbidities, laparoscopic posterior retroperitoneal adrenalectomy can be safely performed in patients with Cushing's syndrome, and in patients with bilateral involvement, it offers the advantage of not having to reposition the patient.

\section{Cortical-Sparing Adrenalectomy}

The concept of cortical-sparing adrenalectomy developed in an effort to preserve functioning adrenal cortex to avoid the need for lifelong glucocorticoid and mineralocorticoid replacement. It was initially applied to patients with bilateral pheochromocytomas or for patients who have previously undergone a contralateral adrenalectomy [17••, 24, 36-38]. Traditionally, this has been done via an open approach; however, it has been shown to be possible via the posterior retroperitoneoscopic approach for patients with pheochromocytoma, Cushing's syndrome, hyperaldosteronism or for patients who have previously undergone contralateral adrenalectomy [5, 24, 34, 37-40]. Yip et al. [36] reported their experience with patients with hereditary pheochromocytoma; 26 patients underwent bilateral cortical-sparing adrenalectomy, and 17 (65\%) of those patients were corticosteroid-independent at a median follow up of 71 months. Alesina et al. [34] published their experience with posterior retroperitoneoscopic adrenalectomy for Cushing's syndrome; of the 170 patients, 35 (21\%) had a partial adrenalectomy. None of the 35 patients had 
persistent or recurrent hypercortisolism. Similarly, He et al. reported their series of 87 patients undergoing corticalsparing adrenalectomy for Cushing's syndrome (31 via open approach and 56 by posterior retroperitoneoscopic approach) and demonstrated a cure rate of $97.8 \%$. In those patients in whom the posterior retroperitoneoscopic approach was performed, benefits included a shorter operating time (80 vs. $125 \mathrm{~min}, p<0.01$ ), hospital lengthof-stay ( 7 vs. 11 days, $p<0.01$ ), and intraoperative complication rate (1.7 vs. $9.1 \%, p<0.05)$ [39]. Overall, cortical-sparing adrenalectomy has been shown to be feasible in patients with varying pathologies via the posterior retroperitoneoscopic approach and is an attractive option for patients undergoing bilateral procedures as it eliminates the need for repositioning.

\section{Future Advances}

\section{Single-Access Laparoscopic Retroperitoneal Adrenalectomy}

Recently Walz et al. [41] reported a series of 50 singleaccess posterior retroperitoneoscopic adrenalectomies in patients with pheochromocytoma, Cushing's syndrome, and hyperaldosteronism. The technique involves the standard incision below the tip of the 12th rib and after the retroperitoneal space is created, two 5-mm ports are inserted through this incision and are used to complete the operation. This group of 50 patients was compared to a group of 47 patients who underwent posterior retroperitoneoscopic adrenalectomy via the standard three-port approach. The single-access approach was completed in $41(86 \%)$ patients with a complication rate of $8.5 \%$ (compared to $6.4 \%$ in standard group, $p=\mathrm{NS})$. Although operative time was longer (56 \pm 28 vs. $40 \pm 12 \mathrm{~min}, p<0.05$ ), patients in the single-access group less frequently needed pain medication (47 vs. $75 \%, p=0.01$ ) and had shorter hospital stays $(2.4 \pm 0.7$ vs. $3.1 \pm 1.2$ days, $p<0.01)$. The authors concluded that this technique may offer a viable new technique for posterior retroperitoneoscopic adrenalectomy [41].

\section{Conclusions}

Since the introduction of laparoscopic posterior retroperitoneal adrenalectomy, it has been shown to be a safe and effective approach for a variety of adrenal pathologies, including non-functioning tumors, ACTH-independent or -dependent hypercortisolism (including ACTH-dependent bilateral hyperplasia), pheochromocytoma, primary hyperaldosteronism, virilizing adenoma, and adrenal metastases.
It can be the preferred technique for some patients, particularly those with prior abdominal operations and patients with bilateral disease. Importantly, it has been shown to be as safe as the transabdominal approach when performed by experienced surgeons, and represents an important technique in the armamentarium of the adrenal surgeon.

Disclosure No potential conflicts of interest relevant to this article were reported.

\section{References}

Papers of particular interest, published recently, have been highlighted as:

•- Of major importance

1. Gagner M, Lacroix A, Bolte E. Laparoscopic adrenalectomy in Cushing's syndrome and pheochromocytoma. N Engl J Med. 1992;327:1033.

2. Mercan S, Seven R, Ozarmagan S, Tezelman S. Endoscopic retroperitoneal adrenalectomy. Surgery. 1995;118:1071-5. discussion 1075-1076.

3. Walz MK, Peitgen K, Hoermann R, Giebler RM, Mann K, Eigler FW. Posterior retroperitoneoscopy as a new minimally invasive approach for adrenalectomy: results of 30 adrenalectomies in 27 patients. World J Surg. 1996;20:769-74.

4. Walz MK, Peitgen K, Diesing D, Petersenn S, Janssen OE, Philipp T, et al. Partial versus total adrenalectomy by the posterior retroperitoneoscopic approach: early and long-term results of 325 consecutive procedures in primary adrenal neoplasias. World J Surg. 2004;28:1323-9.

5. Walz MK, Gwosdz R, Levin SL, Alesina PF, Suttorp AC, Metz $\mathrm{KA}$, et al. Retroperitoneoscopic adrenalectomy in Conn's syndrome caused by adrenal adenomas or nodular hyperplasia. World J Surg. 2008;32:847-53.

6. Walz MK, Peitgen K, Walz MV, Hoermann R, Saller B, Giebler $\mathrm{RM}$, et al. Posterior retroperitoneoscopic adrenalectomy: lessons learned within 5 years. World J Surg. 2001;25:728-34.

7. Walz MK, Alesina PF, Wenger FA, Deligiannis A, Szuczik E, Petersenn S, et al. Posterior retroperitoneoscopic adrenalectomy-results of 560 procedures in 520 patients. Surgery. 2006;140:943-8. discussion 948-950.

8. Perrier ND, Kennamer DL, Bao R, Jimenez C, Grubbs EG, Lee $\mathrm{JE}$, et al. Posterior retroperitoneoscopic adrenalectomy: preferred technique for removal of benign tumors and isolated metastases. Ann Surg. 2008;248:666-74.

9. •- Dickson PV, Jimenez C, Chisholm GB, Kennamer DL, Ng C, Grubbs EG, et al. Posterior retroperitoneoscopic adrenalectomy: a contemporary american experience. J Am Coll Surg. 2011; 212:659-665; discussion 665-667. This paper is an update on the initial experience at this institution.

10. Berber E, Sipperstein A. Laparoscopic retroperitoneal adrenalectomy: posterior approach. Oper Tech Gen Surg. 2002;4:331.

11. • Taskin HE, Siperstein A, Mercan S, Berber E. Laparoscopic posterior retroperitoneal adrenalectomy. J Surg Oncol. 2012; 106:619-621. This paper is a review on retroperitoneoscopic adrenalectomy.

12. Lee J. Laparoscopic retroperitoneal adrenalectomy. In: Duh QY, Clark $\mathrm{OH}$, Kebebew E, editors. Atlas of Endocrine Surgical Techniques. Philadelphia: Elsevier; 2010. p. 194. 
13. Giebler RM, Walz MK, Peitgen K, Scherer RU. Hemodynamic changes after retroperitoneal $\mathrm{CO}_{2}$ insufflation for posterior retroperitoneoscopic adrenalectomy. Anesth Analg. 1996;82: 827-31.

14. Giebler RM, Behrends M, Steffens T, Walz MK, Peitgen K, Peters J. Intraperitoneal and retroperitoneal carbon dioxide insufflation evoke different effects on caval vein pressure gradients in humans: evidence for the starling resistor concept of abdominal venous return. Anesthesiology. 2000;92:1568-80.

15. Rubinstein M, Gill IS, Aron M, Kilciler M, Meraney AM, Finelli A, et al. Prospective, randomized comparison of transperitoneal versus retroperitoneal laparoscopic adrenalectomy. J Urol. 2005;174:442-5. discussion 445.

16. Berber E, Tellioglu G, Harvey A, Mitchell J, Milas M, Siperstein A. Comparison of laparoscopic transabdominal lateral versus posterior retroperitoneal adrenalectomy. Surgery. 2009;146: 621-5. discussion 625-626.

17. • Lee CR, Walz MK, Park S, Park JH, Jeong JS, Lee SH, et al. A comparative study of the transperitoneal and posterior retroperitoneal approaches for laparoscopic adrenalectomy for adrenal tumors. Ann Surg Oncol. 2012;19:2629-2634. This paper compares transperitoneal and retroperitoneal approaches and finds lower analgesia requirements for the retroperitoneoscopic approach.

18. Ramacciato G, Nigri GR, Petrucciani N, Di Santo V, Piccoli M, Buniva $\mathrm{P}$, et al. Minimally invasive adrenalectomy: a multicenter comparison of transperitoneal and retroperitoneal approaches. Am Surg. 2011;77:409-16.

19. Kiriakopoulos A, Economopoulos KP, Poulios E, Linos D. Impact of posterior retroperitoneoscopic adrenalectomy in a tertiary care center: a paradigm shift. Surg Endosc. 2011;25:3584-9.

20. Tai CK, Li SK, Hou SM, Fan CW, Fung TC, Wah MK. Laparoscopic adrenalectomy: comparison of lateral transperitoneal and lateral retroperitoneal approaches. Surg Laparosc Endosc Percutan Tech. 2006;16:141-5.

21. Nigri G, Rosman AS, Petrucciani N, Fancellu A, Pisano M, Zorcolo L, et al. Meta-analysis of trials comparing laparoscopic transperitoneal and retroperitoneal adrenalectomy. Surgery. 2013; 153:111-9.

22. • Agcaoglu O, Sahin DA, Siperstein A, Berber E. Selection algorithm for posterior versus lateral approach in laparoscopic adrenalectomy. Surgery. 2012;151:731-735. This paper describes criteria for choosing a posterior or transabdominal approach for laparoscopic adrenalectomy.

23. Walz MK, Petersenn S, Koch JA, Mann K, Neumann HP, Schmid $\mathrm{KW}$. Endoscopic treatment of large primary adrenal tumours. Br J Surg. 2005;92:719-23.

24. Walz MK, Alesina PF, Wenger FA, Koch JA, Neumann HP, Petersenn S, et al. Laparoscopic and retroperitoneoscopic treatment of pheochromocytomas and retroperitoneal paragangliomas: results of 161 tumors in 126 patients. World J Surg. 2006;30: 899-908.

25. Dickson PV, Alex GC, Grubbs EG, Ayala-Ramirez M, Jimenez C, Evans DB, et al. Posterior retroperitoneoscopic adrenalectomy is a safe and effective alternative to transabdominal laparoscopic adrenalectomy for pheochromocytoma. Surgery. 2011;150: $452-8$.

26. Li QY, Li F. Laparoscopic adrenalectomy in pheochromocytoma: retroperitoneal approach versus transperitoneal approach. J Endourol. 2010;24:1441-5.

27. Gockel I, Vetter G, Heintz A, Junginger T. Endoscopic adrenalectomy for pheochromocytoma: difference between the transperitoneal and retroperitoneal approaches in terms of the operative course. Surg Endosc. 2005;19:1086-92.

28. Cheah WK, Clark OH, Horn JK, Siperstein AE, Duh QY. Laparoscopic adrenalectomy for pheochromocytoma. World J Surg. 2002;26:1048-51.

29. Jaroszewski DE, Tessier DJ, Schlinkert RT, Grant CS, Thompson GB, van Heerden JA, et al. Laparoscopic adrenalectomy for pheochromocytoma. Mayo Clin Proc. 2003;78:1501-4.

30. Kercher KW, Park A, Matthews BD, Rolband G, Sing RF, Heniford BT. Laparoscopic adrenalectomy for pheochromocytoma. Surg Endosc. 2002;16:100-2.

31. Nau P, Demyttenaere S, Muscarella P, Narula V, Hazey JW, Ellison EC, et al. Pheochromocytoma does not increase risk in laparoscopic adrenalectomy. Surg Endosc. 2010;24:2760-4.

32. Sarkar R, Thompson NW, McLeod MK. The role of adrenalectomy in Cushing's syndrome. Surgery. 1990;108:1079-84.

33. Scott HW Jr, Abumrad NN, Orth DN. Tumors of the adrenal cortex and Cushing's syndrome. Ann Surg. 1985;201:586-94.

34. Alesina PF, Hommeltenberg S, Meier B, Petersenn S, Lahner H, Schmid KW, et al. Posterior retroperitoneoscopic adrenalectomy for clinical and subclinical Cushing's syndrome. World J Surg. 2010;34:1391-7.

35. Fernandez-Cruz L, Saenz A, Benarroch G, Astudillo E, Taura P, Sabater L. Laparoscopic unilateral and bilateral adrenalectomy for Cushing's syndrome. Transperitoneal and retroperitoneal approaches. Ann Surg. 1996;224:727-34. discussion 734-736.

36. Yip L, Lee JE, Shapiro SE, Waguespack SG, Sherman SI, Hoff AO, et al. Surgical management of hereditary pheochromocytoma. J Am Coll Surg. 2004;198:525-34. discussion 534-535.

37. Alesina PF, Hinrichs J, Meier B, Schmid KW, Neumann HP, Walz MK. Minimally invasive cortical-sparing surgery for bilateral pheochromocytomas. Langenbecks Arch Surg. 2012; 397:233-8.

38. Cheng SP, Saunders BD, Gauger PG, Doherty GM. Laparoscopic partial adrenalectomy for bilateral pheochromocytomas. Ann Surg Oncol. 2008;15:2506-8.

39. He HC, Dai J, Shen ZJ, Zhu Y, Sun FK, Shao Y, et al. Retroperitoneal adrenal-sparing surgery for the treatment of Cushing's syndrome caused by adrenocortical adenoma: 8-year experience with 87 patients. World J Surg. 2012;36:1182-8.

40. Kok KY, Yapp SK. Laparoscopic adrenal-sparing surgery for primary hyperaldosteronism due to aldosterone-producing adenoma. Surg Endosc. 2002;16:108-11.

41. Walz MK, Groeben H, Alesina PF. Single-access retroperitoneoscopic adrenalectomy (SARA) versus conventional retroperitoneoscopic adrenalectomy (CORA): a case-control study. World J Surg. 2010;34:1386-90. 